\title{
A new treatment for coconut fibers to improve the properties of cement- based composites - Combined effect of natural latex/pozzolanic materials
}

\author{
Everton Jose da Silva ${ }^{\mathrm{a}, *}$, Maria Lidiane Marques $^{\mathrm{a}}$, Fermin Garcia Velasco ${ }^{\mathrm{b}}$, Celso Fornari Junior ${ }^{\mathrm{b}}$, \\ Francisco Martínez Luzardo ${ }^{\mathrm{b}}$, Mauro Mitsuuchi Tashima ${ }^{\mathrm{c}}$ \\ a Bahia Federal Institute of Education, Science and Technology, Campus Eunápolis, Avenida Jonas David Fadini, s/n, Rosa Neto, CEP 45823-431, Eunápolis, Bahia, Brazil \\ b State University of Santa Cruz, Campus Soane Nazaré de Andrade, Rodovia Jorge Amado, km 16, CEP 45662900, Salobrinho, Ilhéus, Bahia, Brazil \\ ${ }^{\mathrm{c}}$ Universidade Estadual Paulista (UNESP), Faculdade de Engenharia, Campus de Ilha Solteira, Alameda Bahia, 550, CEP 15385-000, Ilha Solteira, São Paulo, Brazil
}

\section{A R T I C L E I N F O}

\section{Keywords:}

Durability

Vegetable fibers

Cement matrix

Silica fume

Metakaolin

\begin{abstract}
A B S T R A C T
This paper presents the results of experimental study with a new coconut fiber-cement composite (CFC). To obtain a material with improved performance in order to decrease the amount of calcium hydroxide present on the fiber surface, four forms of coconut fiber treatment were tested. Some combinations of natural latex, water and pozzolanic materials (silica fume or metakaolin) were evaluated by degradation test and accelerated aging through cycles of wetting and drying CFC samples. To determine the mechanical properties obtained from each treatment, flexural tests on CFC composites were performed. After the flexural tests, the fibers were removed from the specimens and analyzed by scanning electron microscopy (SEM), energy dispersive X-ray spectroscopy (EDX), Fourier Transform Infrared spectroscopy (FTIR) and thermogravimetric analysis (TGA). The results indicate that the treatment carried out with the natural latex polymer film combined with a pozzolan layer improved the performance and durability of the CFC.
\end{abstract}

\section{Introduction}

Natural fibers are considered a renewable material and they can be easily found in nature. Its high availability at relatively low cost when compared to other synthetic fibers, encourages its use in several applications. Natural fibers do not have a specific use, being considered a byproduct which cause environmental problems, mainly related to their disposal.

One of the solutions found for the valorization of natural fibers is its use in Portland cement composites. Several papers reported the benefits of using natural fibers such as interesting mechanical and physical properties [24], reduction in the thermoacoustic transfer [25], low specific weight and reduction in the cost of production $[9,10]$.

Nevertheless, the most important factor affecting the large-scale use of natural fibers is associated with their durability. In the strongly alkaline conditions of Portland cement matrix $(\mathrm{pH}>12)$, caused mainly by the presence of calcium hydroxide (portlandite), an interaction between the constituents of natural fibers and portlandite can occur resulting in its degradation [29]. The other main problem associated with the durability of natural fibers is the mineralization process resulting from the migration of hydrated products of Portland cement to the central cavities, walls and voids of the fibers, thus causing their weakening [33].

Recently, Wei and Meyer [39] proposed two new concepts of mineralization mechanism (calcium hydroxide mineralization and self-mineralization) and four interactional alternate steps for the degradation of natural fibers in cement matrix: degradation of lignin and of part of the hemicellulose leading to the exposure of the holocellulose, degradation of hemicellulose causing a decrease in the integrity and stability of the cell walls, degradation of the intramolecular hydrogen bonding leading to the dispersion of cellulose microfibrils and alkaline hydrolysis of amorphous regions (complete degradation of cellulose microfibrils).

For all cases of degradation of natural fibers, authors are in agreement that natural fibers lose their reinforcement capacity, especially after long curing periods - long periods exposed to alkaline environment [36-38].

To diminish this problem, several efforts have been performed. Most studies are centered on the use of supplementary cementitious materials $[5,8,36-38,40]$ or on the reduction of alkalinity matrix by means of carbonation process $[2,20,28,41]$. At any rate, the natural fiber is in safety conditions since the composite production phase. In both cases,

\footnotetext{
* Corresponding author at: Instituto Federal de Educação, Ciência e Tecnologia da Bahia, Campus Eunápolis, Avenida Jonas David Fadini, s/n. Rosa Neto. CEP: 45823-431 Eunápolis, BA, Brazil.

E-mail address: js_everton@yahoo.com.br (E.J.d. Silva).
} 
the natural fibers are degraded during the first curing period, a fact that inhibits the complete action of natural fibers on the composites.

There are several types of natural fibers that have been used in the production of Portland cement composites [3]. Among these fibers, the use of coconut fibers should be taken into account due to the large volume of residue generated annually. According to the Brazilian Institute of Geography and Statistics [12], the Brazilian coconut production was about 2 million tons in 2015 and approximately $970,000 \mathrm{~m}^{3}$ of coconut residue, being the fiber the main residue.

The use of coconut fibers in composites has been investigated by several researchers [35]. John et al. [13] observed the durability of cementitious matrices with coconut fibers and natural fibers compared with fibers extracted from the mortar of a wall built 12 years previously. In this study, they reported that the fiber of the wall samples contained less lignin, indicating that it had been degraded.

In order to attenuate the propagation of cracks in high performance concrete marine structures, Ramli et al. [23] incorporated coconut fiber into the composition of composites. The experimental results showed that the compressive and flexural strengths of the structures improved up to $13 \%$ and $9 \%$, respectively, with the incorporation of coconut fibers. However, in terms of durability, the chloride penetration, intrinsic permeability, and carbonation depth increased with the increase in fiber content. The authors recommend that the coconut fiber undergo treatment prior to its application in concrete to protect it against degradation.

A possibility, however insufficiently studied, which could eliminate the use of these additives, is the use of natural latex along with pozzolans. In contact with the cement matrix, the latex causes a decrease in the ion transport in the aqueous medium that fills the pores of the cement paste. This may be related to the adsorption of $\mathrm{CH}$ in the polymeric film $[1,6]$. This characteristic, combined with the latex adhesive power to adsorb the pozzolan around the fiber, can provide local pozzolanic reactions in the interior of the cementitious matrix that can protect the coconut fiber surface from the alkaline attack.

Hence, the aim of this paper is to show a new treatment for coconut fibers combining the use of natural latex and pozzolanic materials in order to improve the durability of natural fibers in Portland cement composites. In this way, it is intended to find a solution to the degradation of the fiber inserted into the cementitious matrix.

\section{Experimental program}

\subsection{Materials}

Coconut fibers were supplied by Coquefibras S.A. located in the city of Una Brazil. Coconut fibers present a mean diameter about $0.2 \mathrm{~mm}$. Before their use, fibers were cut with $25 \mathrm{~mm}$ length [30] and, subsequently, dried for $2 \mathrm{~h}$ in an oven at $100^{\circ} \mathrm{C}$.

Natural latex extracted from rubber trees (Hevea brasiliensis) was supplied by Mucambo S.A. and present a concentration of 53\%. The specific gravity of natural latex is $0.97 \mathrm{~kg} / \mathrm{cm}^{3}$. A Brazilian standard Portland cement type V, characterized by its rapid strength development and by the absence of mineral addition on its composition ( $95 \%$ of clinker), was used.
A densified silica fume supplied by Tecnosil Ltda and a metakaolin supplied by Metacaulim do Brasil Ltda were used as pozzolanic materials. It is important to note that the selected pozzolanic materials present different chemical composition: the former is a siliceous pozzolan $\left(91.73 \%\right.$ of $\mathrm{SiO}_{2}, 0.29 \%$ of $\mathrm{Al}_{2} \mathrm{O}_{3}, 0.54 \%$ of $\mathrm{SO}_{3}, 0.37 \%$ of $\mathrm{CaO}$ and other minor components) whereas the latter is an aluminosilicate material $\left(58.39 \%\right.$ of $\mathrm{Al}_{2} \mathrm{O}_{3}, 35.47 \%$ of $\mathrm{SiO}_{2}, 2.71 \%$ of $\mathrm{Fe}_{2} \mathrm{O}_{3}$, $1.44 \%$ of $\mathrm{K}_{2} \mathrm{O}$ and other minor components). The silica fume has a fineness of $21,000 \mathrm{~m}^{2} / \mathrm{kg}$ and the metakaolin $12,000 \mathrm{~m}^{2} / \mathrm{kg}$. Both pozzolans are amorphous materials and several studies have been certified their effectiveness in blended Portland cement mortars and concretes [17].

Sodium hydroxide ( $98 \%$ purity) supplied by Vetec Ltda was used in the preparation of sodium hydroxide solution $(1.7 \%$ of $\mathrm{NaOH})$ in order to simulate the degradation of coconut fibers in high alkaline environments.

\subsection{Equipment}

The flexural strength on thin slabs $(15 \times 25 \times 100 \mathrm{~mm})$ was carried out on a Universal Testing Machine EMIC DL500 using a $0.1 \mathrm{~mm} / \mathrm{min}$ stress rate. The flexural strength was an average of 5 values.

A scanning electron microscopy (SEM) Quanta 250 model associated with X-ray dispersive energy (EDX) was used to assess the structure of natural fibers after exposure to alkaline conditions. Thermogravimetric analysis (DGT-60H model from Shimadzu) of the natural fibers was carried out at $10{ }^{\circ} \mathrm{C} / \mathrm{min}$ in nitrogen atmosphere in the range of $25-550{ }^{\circ} \mathrm{C}$ using alumina crucible. Fourier transformed infrared spectroscopy (FTIR, Nicolet IS10 model) with a wavenumber spectrum between 4000 and $400 \mathrm{~cm}^{-1}$ was used to assess the microstructure of the natural fibers.

\subsection{Coconut fiber treatments}

Different treatments were performed in order to study the durability of coconut fiber. At first, each coconut fiber was immersed in an adherent solution (deionized water or natural latex) for $1 \mathrm{~min}$. In this step, the adherent solution surrounds the coconut fiber generating bonding layers. After that, pozzolanic materials (silica fume or metakaolin) were used as coating agent. Pozzolans adhere to the coconut fiber through the adherent solution. The methodology of this new treatment is similar to the preparation of "chicken fingers".

The different combinations of both the adherent solution and coating agent are the treatments proposed for coconut fiber (Table 1). The nomenclature adopted for the different treatments is $\mathrm{X}-\mathrm{Y}$, where $\mathrm{X}$ is related to the pozzolanic material ( $S$ for silica fume and $M$ for metakaolin) and $\mathrm{Y}$ is associated with the adherent solution: A for deionized water and L for natural latex. Another sample used in this study, in order to assess the effectiveness of coconut fiber, is called F-N (Table 1). In this case, the coconut fiber is inserted in the Portland cement composite as-received, it means, there is no adherent solution and no pozzolanic material.

For degradability tests, a coconut fiber sample called NAT was used

Table 1

Treatments carried out on the surface of the coconut fibers.

\begin{tabular}{|c|c|c|c|}
\hline Treat. & Coating & Adherent solution & Details \\
\hline S-A & Silica fume & Water & $\begin{array}{l}\text { Coconut fibers inserted into a deionized water solution for } 60 \text { s under constant agitation. Subsequently, the fibers were placed in a } \\
\text { recipient filled with silica fume. The coconut fiber started to be coated with a layer of silica fume on its surface. }\end{array}$ \\
\hline S-L & Silica fume & Latex & Same S-A treatment procedure, but replacing the deionized water solution with a natural latex solution of $1 \%$ concentration. \\
\hline M-A & Metakaolin & Water & Same S-A treatment procedure, but substituting silica fume for metakaolin. \\
\hline M-L & Metakaolin & Latex & Same M-A treatment procedure, but replacing silica fume with metakaolin. \\
\hline F-N & No & No & $\begin{array}{l}\text { Natural coconut fiber (without any treatment) but inserted into the cementitious matrix for the production of specimens used in the } \\
\text { durability test and, subsequently, removed for FTIR, SEM, EDX and TGA analyses. }\end{array}$ \\
\hline
\end{tabular}




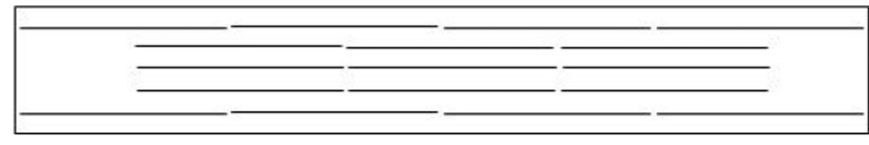

Fig. 1. Arrangement of coconut fibers in the composite specimens (top view).

as a control sample. This fiber was just cut and dried and it was used as a control sample in order to assess the effect of coconut fiber treatment on the degradability test.

\subsection{Preparation of Portland cement composites}

Portland cement was mixed with water (water/binder ratio 0.4). The mixture was stirred at low speed $(124 \mathrm{rpm})$ for $1 \mathrm{~min}$ and at medium speed $(220 \mathrm{rpm})$ for 1 more min. Prismatic molds $\left(15 \times 25 \times 100 \mathrm{~mm}^{3}\right)$ were filled with fresh paste up to $3 \mathrm{~mm}$ height. A set of 17 coconut fibers were properly arranged (Fig. 1) in each prismatic mold. Then, the molds were completely filled with fresh paste and compacted, and finally cured in a humidity chamber at $25{ }^{\circ} \mathrm{C}$. Specimens were demolded after $24 \mathrm{~h}$ and cured in water for 28 days.

\subsection{Tests performed}

\subsubsection{Degradation study}

A degradation study was performed using a sodium hydroxide solution $(1.7 \%)$ at $28{ }^{\circ} \mathrm{C}$ in order to simulate the degradation process of natural fibers that can occur in cementitious composites during the curing time. This process has a similar alkalinity as that in cement composites $(\mathrm{pH} \sim 12.4)$. Coconut fibers (treated and untreated samples) were immersed in the alkaline solution for 60 days, following Silva et al. [31].

\subsubsection{Durability studies}

After 28 curing days, half of prismatic specimens were subjected to flexural loads three-point bending tests were performed (Fig. 2). The other specimens were subjected to dry-wet cycles (a total of 14 cycles). Each cycle takes $48 \mathrm{~h}$ and consists of $24 \mathrm{~h}$ of drying in an oven at $80 \pm 5{ }^{\circ} \mathrm{C}$, and $24 \mathrm{~h}$ immersed in water at $80^{\circ} \mathrm{C}$ [36-38]. After 14 cycles, prismatic specimens were tested in flexion. The flexural property indices were calculated as following:

$\sigma f=\frac{3 \cdot F \cdot L}{2 \cdot b \cdot h^{2}}$

$\mathrm{Ef}=\frac{\mathrm{L}^{3} \cdot \mathrm{m}}{4 \mathrm{bh}^{3}}$

Where of is bending stress (MPa), $F$ is the maximum load (N), L is the span of specimens in three-point bending test (m), Ef is flexural modulus (GPa), b and $h$ are the width and thickness of specimens

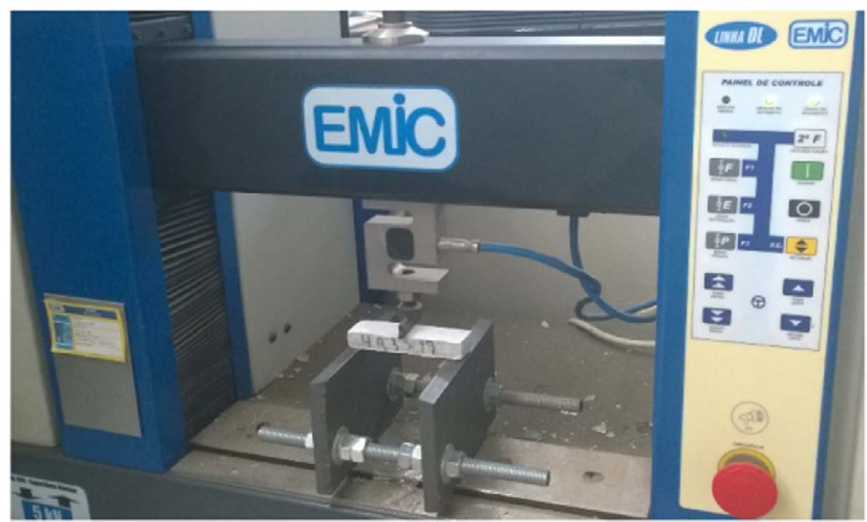

Fig. 2. Flexural strength three-point bending tests.

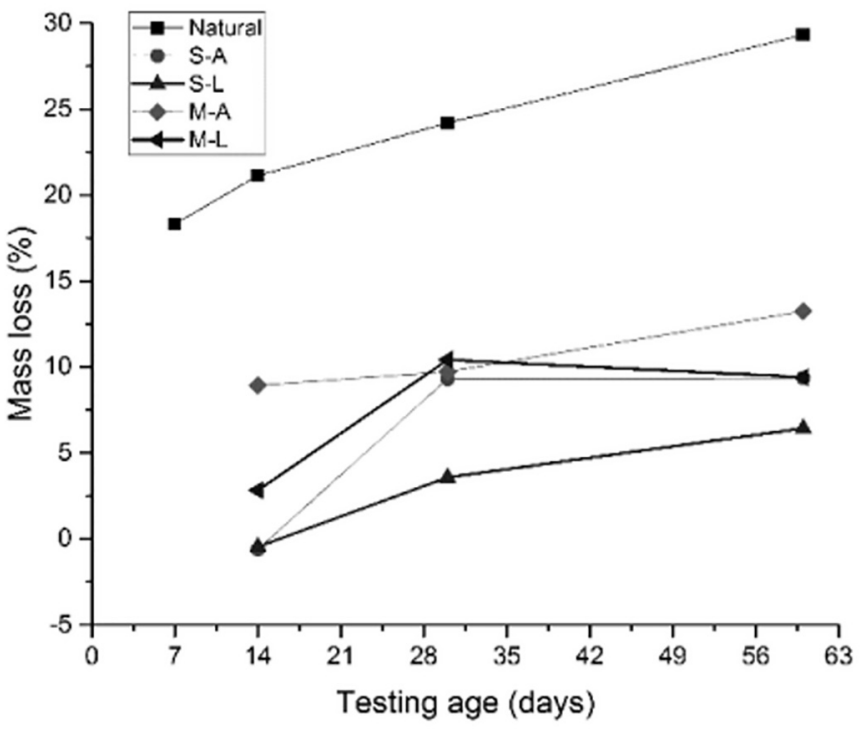

Fig. 3. Mass loss (\%) of coconut fibers subjected to degradation test.

(m), respectively.

After flexural tests were performed, selected coconut fibers were extracted from the CFCs and they were characterized by means of SEM/ EDX, TGA and FTIR.

\section{Results and discussion}

\subsection{Degradation study}

Fig. 3 shows the mass loss (\%) of coconut fibers for different testing ages. As control, a natural coconut fiber (without any treatment) was exposed to the same alkaline solution. For natural fibers, a very significantly mass loss (18.3\%) is yielded during the first 7 testing days. After 60 days of tests, the mass loss yielded around $29.3 \%$. As it was expected, the coconut fiber is degraded in alkaline solution as reported in the literature [26].

When coconut fibers are treated using different combinations of adherent solution and coating agent, an experimental problem occurs in the degradation test: a significant amount of coating agents (silica fume or metakaolin) starts to unglue from the treated coconut fibers when in contact with a high volume of alkaline solution $(60 \mathrm{ml})$. In another word, the mass loss of treated fibers is mainly because of the loss of coating agents not fiber deterioration. Due to this experimental problem, a high mass loss is observed in treated fibers before 7 curing days. Hence, the authors decided to adopt the mass after 7 testing days as the initial mass for treated fibers.

A very significant reduction in the mass loss can be noted. When coated using metakaolin, M-A fibers showed a $13.3 \%$ mass loss reduction and M-L fibers a $9.4 \%$ rate after 60 testing days. For the silica fume coating agent, $9.3 \%$ and $6.4 \%$ mass loss were obtained after 60 testing days for S-A and S-L, respectively.

Comparing these results to the untreated coconut fibers, a reduction in the mass loss for all treated fibers was noted, indicating that all proposed treatments can improve the durability of coconut fibers. Possibly, due to the small difference of mass loss in the period between 30 and 60 days of the treated samples, there was a stabilization of the mass loss for these samples.

The chemical composition and tensile strength of vegetable fibers were investigated by Ref. [22]. Three immersion media were used: pure water, lime saturated water and sodium hydroxide. The authors conclude that the sodium hydroxide solution causes the greatest change in the chemical composition, and also the greatest loss of tensile strength among the studied methods. Wang and Huang [35] treated 

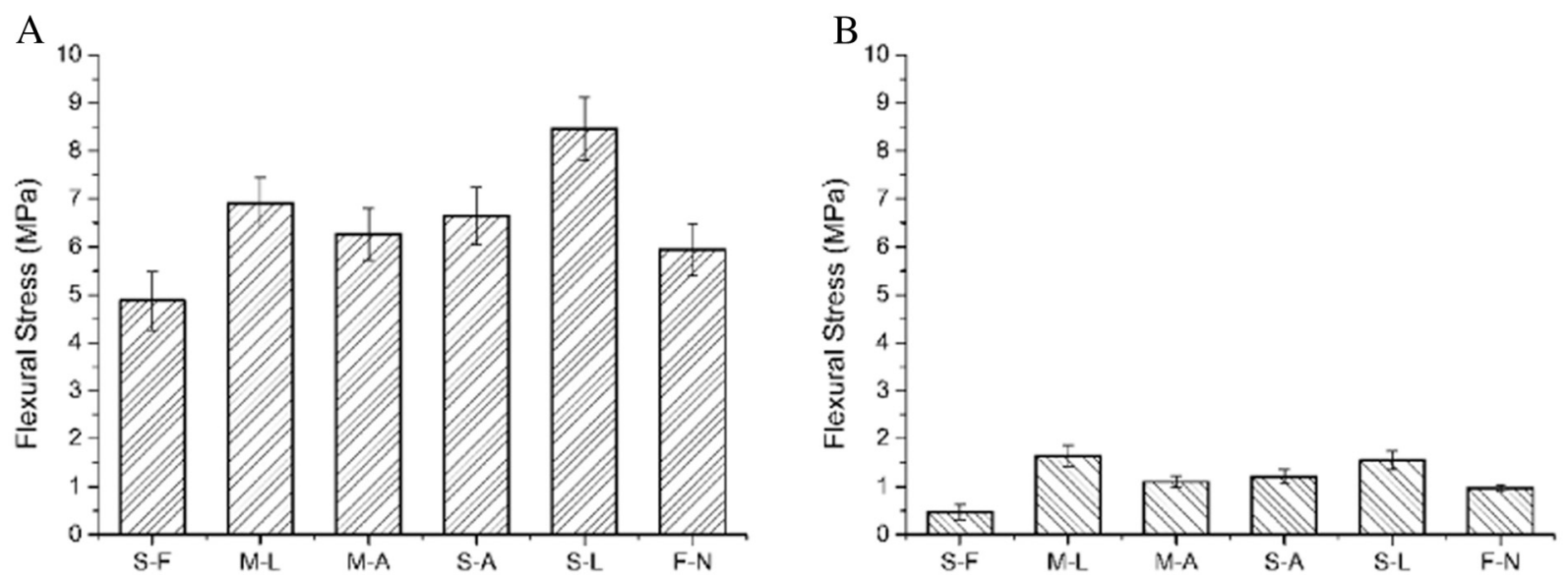

Fig. 4. Flexural stresses of the samples ruptured after 28 days of age (A); Flexural test of the samples ruptured after 28 days of age and cycles of wetting and drying (B).

coconut fibers in $\mathrm{NaOH}$ solutions with concentrations varying from 2 to $10 \%$ for four weeks. The authors observed a decrease tendency in the tensile strength of coconut fibers according to the concentration increase of $\mathrm{NaOH}$ due to fragiliazation of the fibers.

It is expected that the greatest mass loss (higher degree of degradation), verified in the NAT (natural coconut fiber) sample of the present work may be associated with the reduction of tensile strength due to the increase in the percentage of $\mathrm{NaOH}$, reported by Ramakrishna and Sundararajan [22] and Wang and Huang [35]. Thus, it is inferred that the protective effect of the treatment carried out with less mass loss should allow the development of more resistant composites.

\subsection{Durability studies}

The result of the flexural strength test after 28 days of curing is shown in Fig. 4A. The addition of 17 units of coconut fibers with a length of $25 \mathrm{~mm}$ improved the performance of cementitious composites. Furthermore, the results of the variance analysis showed the existence of significant differences among all treatments, with a confidence level $>0.95$ in both curing conditions.

The F-N sample (natural coconut fibers - no treatment) performed around $22 \%$ higher than the specimens without coconut fibers (S-F sample). This difference can be attributed to the mechanical effect that the coconut fibers have on the cement matrix when it is subjected to tensile stresses. Ramli et al. [23] showed 9\% gains on the flexural behavior of concrete with the addition of coconut fiber as compared to the control concrete. Furthermore, the surface roughness of coconut fibers (projections arranged in rows of small nodules) may assist in adherence of the matrix during the curing process and improve interfacial stresses.

From the treatment carried out on the fibers, the values of flexural stress of the M-A and S-A composite samples based on treated fibers were higher by 5.2 and $11.8 \%$ compared to the F-N sample, respectively. Regarding the S-F sample, the difference was of 28.3 and $36.3 \%$, respectively. This demonstrates that the treatment using water as adherent solution and pozzolans on the fiber surface improves the CFC.

The use of natural latex as adherent solution showed even better results than treatment with water. The performance of M-L and S-L samples was 16.1 and $42.2 \%$ better than the F-N sample. When the comparison is carried out with the S-F sample, the difference increases to 41.6 and $73.4 \%$, respectively. This result demonstrates the performance improvement that the incorporation of fiber treated with silica fume and latex (S-L sample) provides. Furthermore, according to Duncan's multiple range test, the performance of the S-L sample is significantly higher than other samples, indicating that the combination between silica fume and latex increased the CFC performance.
As well as in the degradation test, the durability test results indicate that the greatest amount of pozzolan adhered to the surface of coconut fibers (due to the latex adhesive film) may have provided a local pozzolanic effect in the fiber-cement interface. This pozzolanic reaction consumes portlandite $(\mathrm{CH})$ and generates silicates and hydrated calcium aluminates $\left(\mathrm{CSH}\right.$ and $\mathrm{C}_{4} \mathrm{AH}_{\mathrm{x}}$ ) which decrease the local $\mathrm{pH}$ and increase the resistance and cohesion in the fiber-cement mixture [11].

The performance difference between the silica fume and metakaolin pozzolans can be explained by the higher reactivity and lower grading of silica fume. Santos et al. [27] investigated the use of colloidal silica in Portland cement mixture with cellulosic fibers. The authors found that the pullout energy of the fibers is increased significantly in fiber cement composites with the addition of between 3 and 10\% silica. They also noted an improvement in the values of the fracture energy of the specimens.

Fig. 4B shows the effects that the accelerated aging through cycles of wetting and drying has on the samples. With a total duration of $48 \mathrm{~h}$, each of the 14 cycles was carried out in $24 \mathrm{~h}$ of drying in an oven at $80 \pm 5{ }^{\circ} \mathrm{C}$, and $24 \mathrm{~h}$ of water immersion, also at the temperature of $80 \pm 5{ }^{\circ} \mathrm{C}$. This variation in accelerated aging at elevated temperatures proved a reduction of approximately $940 \%$ in the strength of the sample without fibers (S-F) and of approximately $450 \%$ for S-L and M-L samples due to the great fragility of the cementitious matrix connections. Its brittle behavior was maximized by the curing conditions, with a sudden drop in strength after the appearance of the first crack. On the other hand, the sample with coconut fiber (F-N) had approximately twice the strength of the S-F sample, while the M-L and S-L samples had about three times the strength compared to the S-F sample. After the cracking, the presence of the fibers may have hardened the weak points in the matrix caused by the accelerated aging by means of seams which promoted a rearrangement of stresses within the composite.

By comparing treated coconut fibers with the untreated ones (F-N), the performance difference of the M-L and S-L samples are significantly higher (70.1 and 59.8\%, respectively), in accordance with Duncan's test. Furthermore, it was observed that even without the latex adhesive power, the samples, which used water as adherent solution, were also able to improve the durability of the composite. The M-A and S-A samples showed improvements of 13.4 and $24.7 \%$ compared with the F$\mathrm{N}$ sample. As in the curing conditions at 28 days, the association between latex and pozzolan was also more effective in the aggressive conditions of disruption of specimens after the curing process. This behavior shows that local pozzolanic reactions were able to provide protection to the coconut fibers in the accelerated aging conditions of the specimens.

Regarding the elastic modulus, there is a performance in this property due to the better deformability stemming from the presence 
A

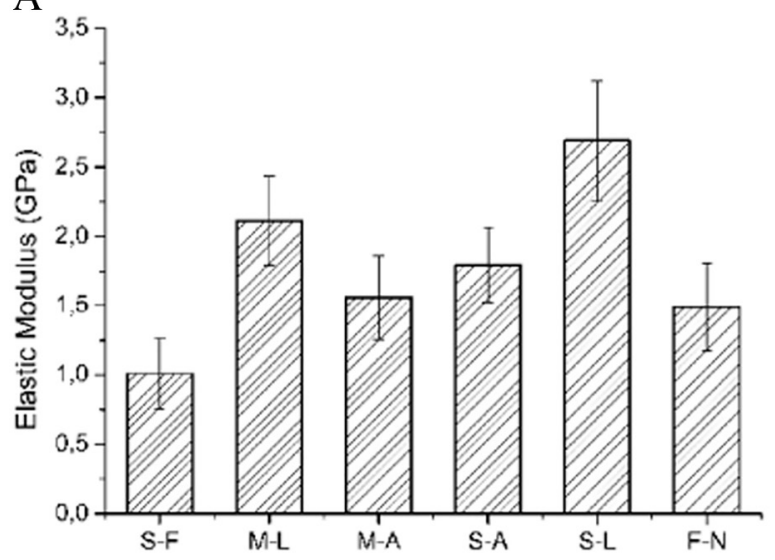

B

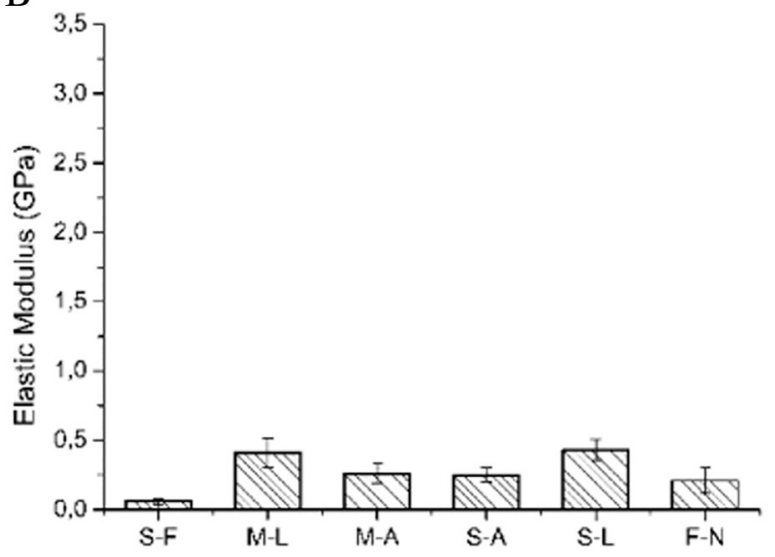

Fig. 5. Elastic modulus after 28 days of age (A); elastic modulus after 28 days of age and cycles of wetting and drying (B).

of fibers in the CFCs compared with the S-F sample. Similar results were verified by Savastano et al. [29]. Both in Fig. 5A as in Fig. 5B, it is observed that the M-L and S-L samples demonstrate a greater elastic modulus. This is due to the higher load capacity and low deformation obtained by the coconut fibers with a coating layer formed by the interaction of the latex film and the pozzolan within the composite.

In relation to the F-N sample, the M-L and S-L samples showed improve of 41.6 and $80.5 \%$ after 28 days of curing; and of 95.3 and $104.8 \%$ after curing cycles. It can also be seen that the performance of the S-L sample was $166 \%$ better than the S-F one after 28 days and $616.7 \%$ in curing cycles. This difference can be explained by the low alkalinity zone around the fiber created by the silica fume present in the fiber-matrix interface. This phenomenon delays or prevents fiber degradation by alkaline attack or mineralization by $\mathrm{CH}$ migration [34]. In addition to the pozzolanic effect, it is also possible that the reduction in the available space caused by the polymeric film of natural latex decreased the transport of ions in the water, which in turn reduces the quantity of $\mathrm{CH}$ generated in the hydration process $[1,6]$. The interconnection of these phenomena explains the increase in the mechanical strength and durability of the composites studied in this work.

Through Fig. 6A and B (images of the ruptured specimens 20 times increased) it is found that while the treated fibers, mainly with latexpozzolan, remain more intact and flexible to the touch, untreated fibers have lost their ductility. In addition, it is noted that the variation of humidity at high temperature caused by the accelerated aging created a large porosity in the fiber-matrix transition zone in the untreated coconut fiber sample.

Ardanuy et al. [3] approach the increase in durability of cementi- tious composites with vegetable fibers in two ways. In this study, both treatments are used, namely a surface treatment of the coconut fibers with a polymeric film of natural latex combined with a pozzolan layer. In accordance with the authors, the treatment applied in the present study causes local pozzolanic reactions that modify both the cementitious matrix around the fiber as well as the fiber surface, which prevents the alkaline attack and the mineralization of the fibers.

\subsubsection{Scanning electron microscopy and energy dispersive $X$-ray spectroscopy (SEM/EDX)}

The SEM images were taken after the extraction of the fibers from inside the specimens which were subjected to a flexural strength test in the two curing conditions. In Fig. 7A, it is observed that there are small irregularities on the surface of the coconut fiber. The cuticle coats the coconut fiber and the globular particles are presented as protrusions fixed in specific pits of the fiber itself. These irregularities create an irregular morphology on the coconut fiber [18]. According to the EDX analysis in the present work, the natural coconut fiber sample (NAT) has approximately $51 \%$ carbon and $46 \%$ oxygen as its main constituent elements, which make up the composition of the fiber, that is, cellulose, hemicellulose, lignin, pectin and extractives.

After the insertion of fibers into the specimens, a difference could be found between the natural fiber and the fibers removed from the specimens after the curing process. This difference can cause changes to the fiber surface, as can be seen on Fig. 7B, C and D. Cement hydration products could be observed on the fiber surface, as well as evidence of degradation in the F-N sample, probably due to the fact that this sample had not received protective treatment. From the data obtained by EDX, it is observed that the F-N sample registered the presence of approxi-
A

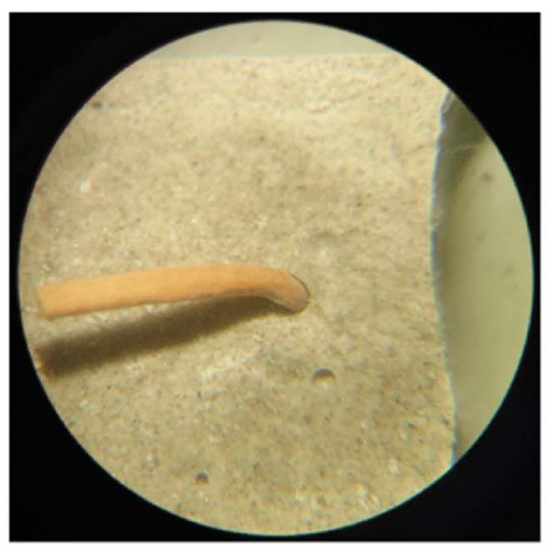

B

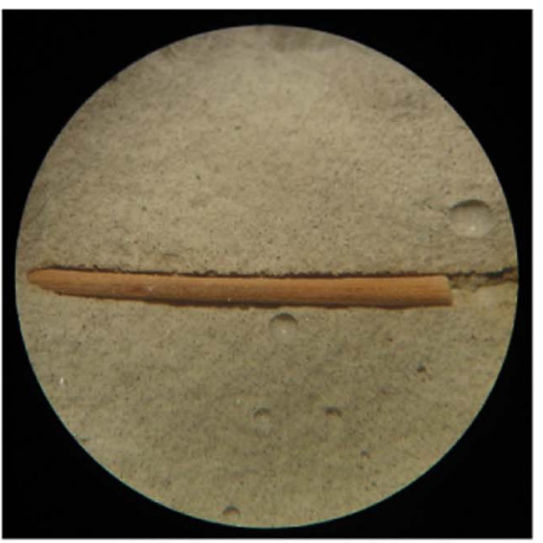

Fig. 6. Image of S-L samples (A) and F-N (B). 
A

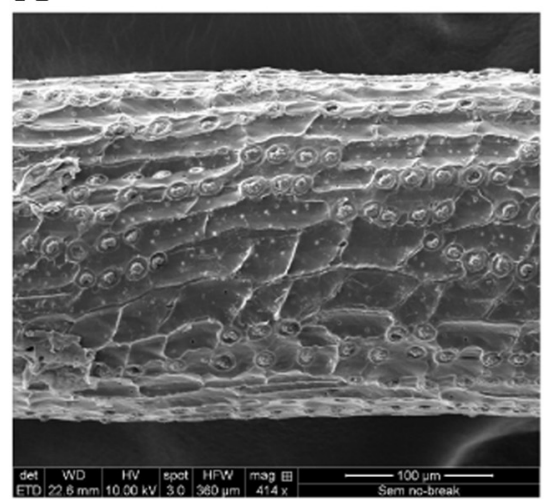

$\mathrm{C}$

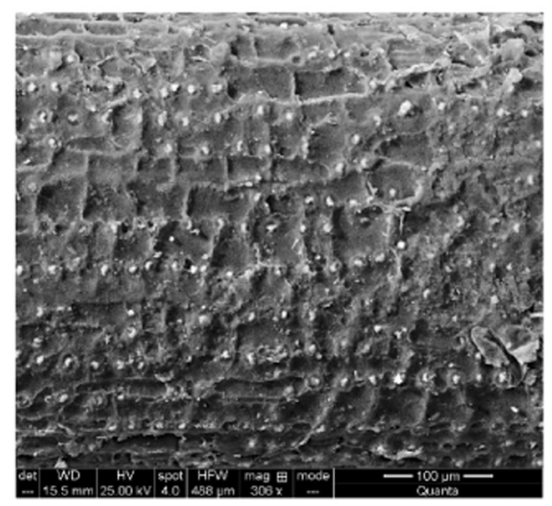

B

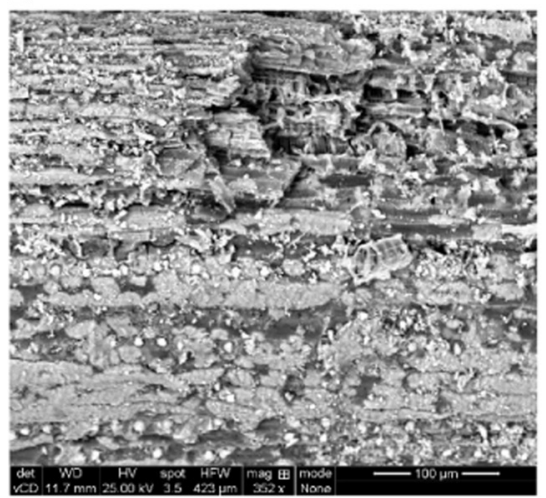

$\mathrm{D}$

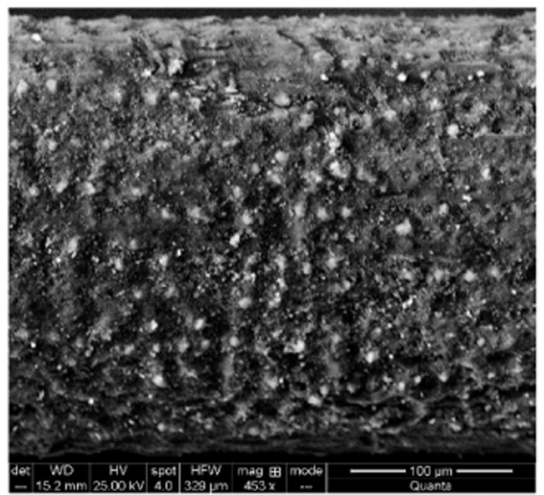

Fig. 7. SEM of NAT samples (A); F-N (B); S-L (C) and M-L (D).

mately $6 \%$ calcium, which did not happen in the NAT sample. This can be explained by the presence of $\mathrm{CH}$ and $\mathrm{CSH}$ on the surface of natural coconut fibers in the cementitious matrix (F-N).

On the S-L and M-L samples, a better conservation of the fiber can be seen compared with the F-N sample. In these samples, the globular particles appear intact, even when they are covered by the hydration products. The M-L sample registered approximately $13 \%$ aluminum and $13 \%$ silicon besides carbon and oxygen in the EDX analysis. This chemical composition refers to the $\mathrm{CSH}$ and $\mathrm{C}_{4} \mathrm{AHx}$, formed from the local pozzolanic reaction that occurred on the surface of the coconut fiber. Possibly, this reaction was responsible for the high mechanical strength obtained in the flexural test. This same mechanism was also observed in the S-L sample, which registered approximately $26 \%$ silicon in its surface composition. The silica fume, with approximately $95 \%$ $\mathrm{SiO}_{2}$ in its composition, produced a large amount of $\mathrm{CSH}$ on the fiber surface, which consumes $\mathrm{CH}$, reduces the $\mathrm{pH}$ and minimizes the porosity on the fiber-matrix interface area.

The use of latex as adherent solution increased the fiber-pozzolan adherence conditions, which contributed to the pozzolanic reaction. In addition, the presence of latex can increase the performance of the cement hydration process, as explained by Plank and Gretz [21]. Regarding the samples in which water was used as an adherent solution, the pozzolanic effect was not so pronounced, which can be attributed to a smaller amount of pozzolan that was deposited on the coconut fiber during the treatment. The analysis by SEM/EDX showed results concordant with those obtained in the degradation and durability tests.

\subsubsection{Thermogravimetric analysis (TGA)}

The thermal decomposition of the vegetable fiber is divided into four stages: the first one is the decomposition of the impregnating water; the second stage is the decomposition of the hemicellulose; the third one is the decomposition of the cellulose; and, lastly, the decomposition of the lignin, according to Martin et al. [15]. For coconut fibers, the hemicellulose degrades firstly due to its amorphous and branched structure composed of saccharides which are decomposed at lower temperatures. Cellulose decomposes afterwards because it has a semicrystalline structure without branching, which leads to a better thermal stability. The lignin, despite having an amorphous structure formed by aromatic compounds with many branches, is decomposed slowly over a wide temperature range [4].

Yang et al. [42] establish some temperature ranges equivalent to the thermal decompositions of each chemical component. The mass loss that occurs, mostly at $220-315^{\circ} \mathrm{C}$, corresponds to hemicellulose. The cellulose is lost mainly at the $315-400{ }^{\circ} \mathrm{C}$ range. Also according to the authors, the lignin is hard to decompose and its range can vary from $160{ }^{\circ} \mathrm{C}$ to $900{ }^{\circ} \mathrm{C}$.

Regarding the hydration products present on the surface of the coconut fibers, Soriano et al. [32] state that the compounds CSH, CAH and hydrated calcium silicoaluminates (CASH) decompose until $220^{\circ} \mathrm{C}$. Moreover, the authors reported that the $\mathrm{CH}$ is decomposed in the range of $500-550{ }^{\circ} \mathrm{C}$.

Table 2 shows the mass loss corresponding to each temperature range of the extracted coconut fibers from the specimens and the natural coconut fiber (NAT), which was not inserted into the cement matrix and did not receive any treatment. It is observed that the whole mass of the NAT is decomposed up to the temperature of $550{ }^{\circ} \mathrm{C}$ with the largest portion $\left(34.62 \%\right.$ ) consumed in the range of $400{ }^{\circ} \mathrm{C}$ to $550{ }^{\circ} \mathrm{C}$, which corresponds to the lignin fraction of coconut fibers, considering that the coconut fibers have approximately $45 \%$ of its mass related to lignin [7]. This quantity is considerably higher in relation to the majority of the treated and untreated fibers inserted in the specimens.

In general, large variations in weight loss were not observed in the range of $25-400{ }^{\circ} \mathrm{C}$ among the samples, which is related to impregnating water, hemicellulose, the cellulose content and the cement hydration products present on the sample surface. In this regard, it is noted 
Table 2

Mass loss of the fiber samples by thermogravimetric analysis.

\begin{tabular}{lllllll}
\hline \multirow{2}{*}{ Sample } & \multicolumn{5}{c}{ Mass loss (\%) in each interval $\Delta \mathrm{T}\left({ }^{\circ} \mathrm{C}\right)$} \\
\cline { 3 - 7 } & & $25-220$ & $220-315$ & $315-400$ & $400-550$ & $<550$ \\
\hline \multirow{2}{*}{ Natural (NAT) } & & 12.07 & 28.28 & 25.03 & 34.62 & 0 \\
28 days & F-N & 13.05 & 23.08 & 19.51 & 16.66 & 27.70 \\
& M-A & 15.14 & 23.81 & 15.81 & 21.96 & 23.28 \\
& M-L & 15.87 & 23.51 & 17.90 & 32.09 & 10.63 \\
& S-A & 14.98 & 23.86 & 19.60 & 30.72 & 10.84 \\
28 days + cycles of & S-L & 14.36 & 24.99 & 19.16 & 13.15 & 28.34 \\
wetting and & F-N & 14.05 & 21.56 & 24.73 & 12.71 & 26.95 \\
drying & M-A & 12.60 & 25.15 & 18.43 & 27.31 & 16.51 \\
& M-L & 11.56 & 21.97 & 23.64 & 26.71 & 16.12 \\
& S-A & 13.55 & 24.66 & 25.77 & 13.70 & 22.32 \\
& S-L & 08.16 & 25.62 & 21.28 & 07.46 & 37.48 \\
\hline
\end{tabular}

that the sample M-L (28 days) had the highest weight loss (15.87\%) in the range of $25-220^{\circ} \mathrm{C}$, possibly attributed to the increased formation of CAH and CASH in this sample, as analyzed by EDX.

The main differences among the samples occur in the range of $400-550{ }^{\circ} \mathrm{C}$, which is the interval corresponding to the fraction of lignin and $\mathrm{CH}$ present around the fiber. The S-L samples had lower weight losses in the two curing conditions (13.15\% for 28 days and $07.46 \%$ for 28 days + cycles of wetting and drying); this behavior is attributed to the fact that the treatment with silica fume and natural latex led to decrease in amount of $\mathrm{CH}$ phase due to the pozzolanic reaction and also decreased the dehydration of the lignin fraction in the fiber in the range of $400-550{ }^{\circ} \mathrm{C}$. Wei and Meyer [39] assuming that the weight loss of the residual components of each sample is the same between 500 and $600{ }^{\circ} \mathrm{C}$, the extra weight loss of the embedded fiber after the main decomposition step can be considered to indicate the amount of $\mathrm{CH}$ precipitated in the cell walls. The fiber embedded in the pure cement matrix yielded a $\mathrm{CH}$ amount of $10.9 \%$. However, the metakaolin $(3.0 \%)$ indicated a considerable inhibiting effect on the mineralization of the fiber.

The decrease of $\mathrm{CH}$ deposition on the surface of the fiber due to the treatment with silica fume and natural latex is important because this deposition may initiate the degradation process of the fibers, which reduces the ductility and resistance of the fibers [16], as evidenced in the flexural strength test in this work.

From the exposed, it is observed that the results of the TGA analysis match the ones obtained in the degradation and durability tests. The samples that used the combination of latex and pozzolan, particularly the S-L sample, led to an increase in the thermal stability of the coconut fibers and, at the same time, contributed to the reduction of degradation of the lignin present on the surface of the coconut fiber.

\subsubsection{Fourier transformed infrared spectroscopy (FTIR)}

Fig. 8 shows the FTIR spectra of natural coconut fiber samples (NAT), untreated natural coconut fibers inserted into the cement matrix (F-N) and the treated coconut fibers inserted into the matrix (S-L) in the infrared region of $700-1800 \mathrm{~cm}^{-1}$. From the analysis of the three spectra, it was observed that the variation among the NAT, F-N and S-L bands was small, seeing that the number of coincidences in each band is high. However, some differences are observed, and they are related to the absence of the $1735 \mathrm{~cm}^{-1}$ and $\approx 1375 \mathrm{~cm}^{-1}$ bands for the F-N and S-L samples. This fact may indicate a loss of the carbonyl group due to the decarboxylation process derived from the basic hydrolysis of lignin caused by the alkaline conditions of the cement hydration [14,19]. John et al. [13] point out that the delignification of the coconut fibers was $14 \%$ after 12 years inside wall panels.

The FTIR analysis in the present work showed that although the S-L sample lost some functional groups, the degradation and durability tests indicated that the treatment associating silica and latex had the best performance. This can be explained by the action of the pozzolanic reaction on the surface of the fiber as observed in analyses carried out by SEM, EDX and TGA. Besides, this fact suggests a possible process of polymerization on the fiber surface when coated with this treatment.

\section{Conclusions}

The coconut fiber treatment developed with latex polymer film and a pozzolan layer improves the flexural strength and durability of the cement-based composites. The performance of treatment with silica fume and natural latex was $42.2 \%$ better than the sample without treatment. This treatment resulted in the greater mass conservation rate in degradation tests of fiber samples. The microstructural analyses of these treated fibers extracted from CFCs indicated an increase in the preservation of the fiber structure against the degradation process. This treatment can be an alternative way to the use of coconut fibers in the development of new cementitious composite materials with adequate performance and durability.

\section{Acknowledgment}

The authors acknowledge the financial support from the Bahia State Research Support Foundation (FAPESB, Project No. 19.573.128.2586), from the Bahia Federal Institute of Education, Science and Technology,

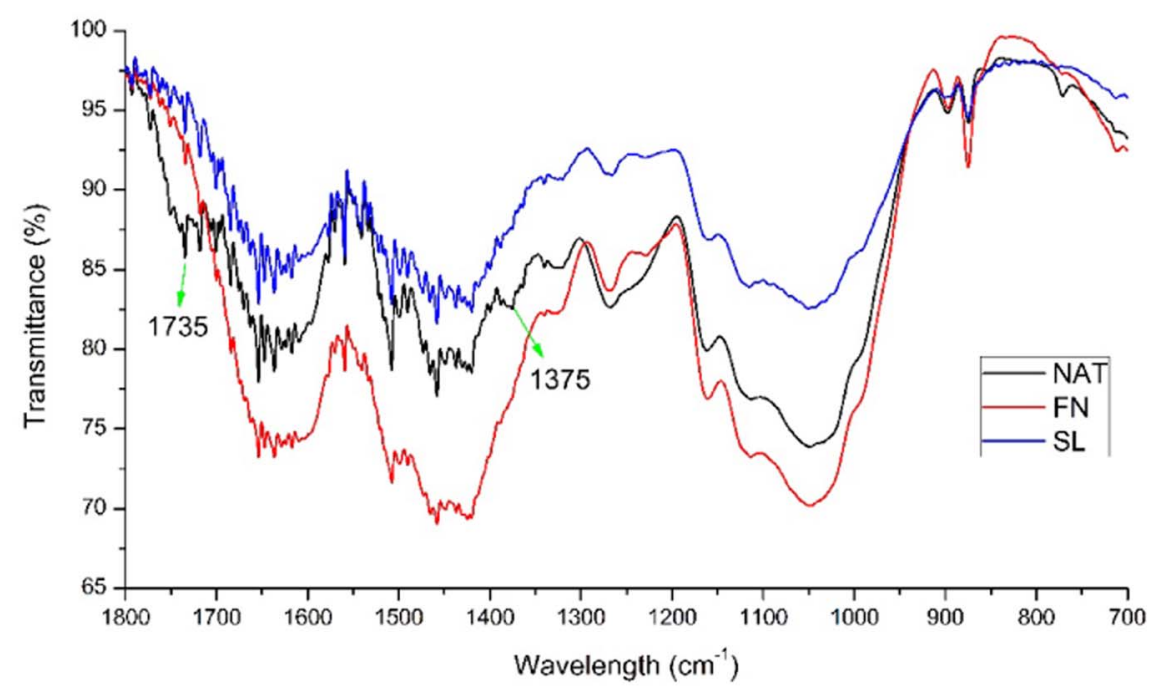

Fig. 8. FTIR of NAT samples, F-N and S-L. 
and technical infrastructure from the State University of Santa Cruz. We would also like to extend special thanks to the Brazilian companies Coquefibras Ltda, Metacaulim Ltda, Mucambo S.A. and Tecnosil Ltda.

\section{References}

[1] M.U.K. Afrid, Y. Ohamat, M. Zafar Iqbal, K. Demura, Behaviour of $\mathrm{Ca}(\mathrm{OH})_{2}$ in polymer modified mortars, Int. J. Cem. Compos. Light. Concr. 11 (1989) 235-244, http://dx.doi.org/10.1016/0262-5075(89)90104-8.

[2] A.E.F.S. Almeida, G.H.D. Tonoli, S.F. Santos, H. Savastano, Improved durability of vegetable fiber reinforced cement composite subject to accelerated carbonation at early age, Cem. Concr. Compos. 22 (2013) 49-58, http://dx.doi.org/10.1016/j. cemconcomp.2013.05.001

[3] M. Ardanuy, J. Claramunt, R.D. Toledo Filho, Cellulosic fiber reinforced cementbased composites: a review of recent research, Constr. Build. Mater. 79 (2015) 115-128, http://dx.doi.org/10.1016/j.conbuildmat.2015.01.035.

[4] G.M. Arifuzzaman Khan, M.S. Alam, M. Terano, Thermal characterization of chemically treated coconut husk fibre, Indian J. Fibre Text. Res. 37 (2012) 20-26.

[5] M.A. Arsène, K. Bilba, H. Savastano Junior, Ghavami, Treatments of non-wood plant fibres used as reinforcement in composite materials, Mater. Res. 16 (2013) 1-21, http://dx.doi.org/10.1590/S1516-14392013005000084.

[6] J. Bijen, Improved mechanical properties of glass fibre reinforced cement by polymer modification, Cem. Concr. Compos. 12 (1990) 95-101, http://dx.doi.org/ 10.1016/0958-9465(90)90046-Z

[7] K. Bilba, M.A. Arsene, A. Ouensanga, Study of banana and coconut fibers. Botanical composition, thermal degradation and textural observations, Bioresour. Technol. 70 (2007) 2741-2744, http://dx.doi.org/10.1016/j.matdes.2008.11.002.

[8] S.R. Ferreira, F.D.A. Silva, P.R.L. Lima, R.D. Toledo Filho, Effect of fiber treatments on the sisal fiber properties and fiber-matrix bond in cement based systems, Constr. Build. Mater. 101 (2015) 730-740, http://dx.doi.org/10.1016/j.conbuildmat.2015. 10.120

[9] K. Gunasekaran, P.S. Kumar, M. Lakshmipathy, Mechanical and bond properties of coconut shell concrete, Constr. Build. Mater. 25 (2011) 92-98, http://dx.doi.org/ 10.1016/j.conbuildmat.2010.06.053.

[10] K. Gunasekaran, R. Annadurai, P.S. Kumar, A study on some durability properties of coconut shell aggregate concrete, Mater. Struct. 48 (2015) 1253-1264, http://dx. doi.org/10.1617/s11527-013-0230-2.

[11] R.M. Gutiérrez, L.N. Díaz, S. Delvasto, Effect of pozzolans on the performance of fiber-reinforced mortars, Cem. Concr. Compos. 27 (2005) 593-598, http://dx.doi. org/10.1016/j.cemconcomp.2004.09.010.

[12] IBGE - Instituto Brasileiro de Geografia e Estatística, Levantamento sistemático da produção agrícola, vol.29, IBGE, Rio de Janeiro, 2015, pp. 1-83.

[13] V.M. John, M.A. Cincotto, C. Sjöström, V. Agopyan, C.T.A. Oliveira, Durability of slag mortar reinforced with coconut fibre, Cem. Concr. Compos. 27 (2005) 565-574, http://dx.doi.org/10.1016/j.cemconcomp.2004.09.007.

[14] F.H.M. Luzardo, F.G. Velasco, C.P. Alves, I.K.S. Correia, L.L. Cazorla, Chemical characterization of agroforestry solid residues aiming its utilization as adsorbents for metals in water, Revista Brasileira de Engenharia Agrícola e Ambiental (2015), http://dx.doi.org/10.1590/1807-1929/agriambi.v19n1p77-83.

[15] A.R. Martin, M.A. Martins, O.R.R.F. Da Silva, L.H.C. Mattoso, Studies on the thermal properties of sisal fiber and its constituents, Thermochim. Acta 506 (2010) 14-19, http://dx.doi.org/10.1016/j.tca.2010.04.008.

[16] J.D.A.M. Melo Filho, F.D.A. Silva, R.D. Toledo Filho, Degradation kinetics and aging mechanisms on sisal fiber cement composite systems, Cem. Concr. Compos. 40 (2013) 30-39, http://dx.doi.org/10.1016/j.cemconcomp.2013.04.003.

[17] M. Mohammadi, R.M. Moghtadae, N.A. Samani, Influence of silica fume and metakaolin with two different types of interfacial adhesives on the bond strength of repaired concrete, Constr. Build. Mater. 51 (2014) 141-150, http://dx.doi.org/10. 1016/j.conbuildmat.2013.10.048.

18] T.H. Nam, S. Ogihara, N.H. Tung, S. Kobayashi, Effect of alkali treatment on interfacial and mechanical properties of coir fiber reinforced poly(butylene succinate) biodegradable composites, Compos. Part B 42 (2011) 1648-1656, http:// dx.doi.org/10.1016/j.compositesb.2011.04.001.

[19] K.K. Pandey, A.J. Pitman, FTIR studies of the changes in wood chemistry following decay by brown-rot and white-rot fungi, Int. Biodeterior. Biodegrad. 52 (2003) 151-160, http://dx.doi.org/10.1016/S0964-8305(03)00052-0.

[20] V.D. Pizzol, L.M. Mendes, H. Savastano, M. Frías, F.J. Davila, M.A. Cincoto, V.M. John, G.H.D. Tonoli, Mineralogical and microstructural changes promoted by accelerated carbonation and ageing cycles of hybrid fiber-cement composites, Constr. Build. Mater. 68 (2014) 750-756, http://dx.doi.org/10.1016/j. conbuildmat.2014.06.055.
[21] J. Plank, M. Gretz, Study on the interaction between anionic and cationic latex particles and Portland cement, Colloids Surf. A Physicochem. Eng. Asp. 330 (2008) 227-233, http://dx.doi.org/10.1016/j.colsurfa.2008.08.005.

[22] G. Ramakrishna, T. Sundararajan, Studies on the durability of natural fibres and the effect of corroded fibres on the strength of mortar, Cem. Concr. Compos. 27 (2005) 575-582, http://dx.doi.org/10.1016/j.cemconcomp.2004.09.008.

[23] M. Ramli, W.H. Kwan, N.F. Abas, Strength and durability of coconut-fiberreinforced concrete in aggressive environments, Constr. Build. Mater. 38 (2013) 554-566, http://dx.doi.org/10.1016/j.conbuildmat.2012.09.002.

[24] R. Rocha Almeida, C. Henrique Soares Del Menezzi, D. Eterno Teixeira, Utilization of the coconut shell of babaçu (Orbignya sp.) to produce cement-bonded particleboard, Bioresour. Technol. 85 (2002) 159-163, http://dx.doi.org/10.1016/S09608524(02)00082-2.

[25] N.J. Rodríguez, M. Yáñez-Limón, F.A. Gutiérrez-Miceli, O. Gomez-Guzman, T.P. Matadamas-Ortiz, L. Lagunez-Rivera, J.A. Feijoo, Assessment of coconut fibre insulation characteristics and its use to modulate temperatures in concrete slabs with the aid of a finite element methodology, Energy Build. 43 (2011) 1264-1272, http://dx.doi.org/10.1016/j.enbuild.2011.01.005.

[26] H. Salmah, M. Marliza, P.L. Teh, Treated coconut shell reinforced unsaturated polyester composites, International Journal of Engineering \& Technology. 13 (2013) 94-103.

[27] S.F. Santos, J.D.A. Rodrigues, G.H.D. Tonoli, A.E.F.D.S. Almeida, H. Savastano, Effect of colloidal silica on the mechanical properties of fiber-cement reinforced with cellulosic fibers, J. Mater. Sci. 49 (2014) 7497-7506, http://dx.doi.org/10. 1007/s10853-014-8455-1.

[28] S.F. Santos, G.H.D. Tonoli, J.E.B. Mejia, J. Fiorelli, H. Savastano, Non-conventiona cement-based composites reinforced with vegetable fibers: a review of strategies to improve durability, Mater. Constr. 65 (2015).

[29] H. Savastano, S.F. Santos, M. Radonjic, W.O. Soboyejo, Fracture and fatigue of natural fiber-reinforced cementitious composites, Cem. Concr. Compos. 31 (2009) 232-243, http://dx.doi.org/10.1016/j.cemconcomp.2009.02.006.

[30] E.J. Silva, P.D. Silva, M.L. Marques, C.C.M. Fornari Jr., F.C. Garcia, F.H.M. Luzardo, Compressive strength of cement mortar prepared with the addition of coconut fiber, Revista Brasileira de Engenharia Agrícola e Ambiental. (2014), http://dx.doi.org/ 10.1590/1807-1929/agriambi.v18n12p1268-1273.

[31] E.J. Silva, M.L. Marques, F.G. Velasco, C.C.M. Fornari Jr., F.H.M. Luzardo, Degradation of coconut fiber immersed in cement and $\mathrm{NaOH}$ alkaline solutions, Revista Brasileira de Engenharia Agrícola e Ambiental (2015), http://dx.doi.org/ 10.1590/1807-1929/agriambi.v19n10p981-988.

[32] L. Soriano, M.M. Tashima, M. Bonilla, J. Payá, J. Monzó, M.V. Borrachero, Use of high-resolution thermogravimetric analysis (HRTG) technique in spent FCC catalyst/Portland cement pastes, J. Therm. Anal. Calorim. 120 (2015) 1511-1517, http://dx.doi.org/10.1007/s10973-015-4526-z.

[33] R.D. Tolêdo Filho, F.A. Silva, E.M.R. Fairbairn, J.A.M. Filho, Durability of compression molded sisal fiber reinforced mortar laminates, Constr. Build. Mater. 23 (2009) 2409-2420, http://dx.doi.org/10.1016/j.conbuildmat.2008.10.012.

[34] F.R. Tolêdo Romildo, K. Ghavami, G.L. England, K. Scrivener, Development of vegetable fibre-mortar composites of improved durability, Cem. Concr. Compos. 25 (2003) 185-196, http://dx.doi.org/10.1016/S0958-9465(02)00018-5.

[35] W. Wang, G. Huang, Characterisation and utilization of natural coconut fibres composites, Mater. Des. 30 (2009) 2741-2744, http://dx.doi.org/10.1016/j matdes.2008.11.002.

[36] J. Wei, C. Meyer, Degradation rate of natural fiber in cement composites exposed to various accelerated aging environment conditions, Corros. Sci. 88 (2014) 118-132, http://dx.doi.org/10.1016/j.corsci.2014.07.029.

[37] J. Wei, C. Meyer, Improving degradation resistance of sisal fiber in concrete through fiber surface treatment, Appl. Surf. Sci. 289 (2014) 511-523, http://dx.doi.org/10. 1016/j.apsusc.2013.11.024.

[38] J. Wei, C. Meyer, Sisal fiber-reinforced cement composite with Portland cement substitution by a combination of metakaolin and nanoclay, J. Mater. Sci. 49 (2014) 7604-7619, http://dx.doi.org/10.1007/s10853-014-8469-810.

[39] J. Wei, C. Meyer, Degradation mechanisms of natural fiber in the matrix of cement composites, Cem. Concr. Res. 73 (2015) 1-16, http://dx.doi.org/10.1016/j. cemconres.2015.02.019.

[40] J. Wei, C. Meyer, Utilization of rice husk ash in green natural fiber-reinforced cement composites: mitigating degradation of sisal fiber, Cem. Concr. Res. 81 (2016) 94-111, http://dx.doi.org/10.1016/j.cemconres.2015.12.001.

[41] J. Wei, S. Ma, D. Thomas, Correlation between hydration of cement and durability of natural fiber-reinforced cement composites, Corros. Sci. 106 (2016) 1-15, http:// dx.doi.org/10.1016/j.corsci.2016.01.020.

[42] H. Yang, R. Yan, H. Chen, D.H. Lee, C. Zheng, Characteristics of hemicellulose, cellulose and lignin pyrolysis, Fuel 86 (2007) 1781-1788, http://dx.doi.org/10. 1016/j.fuel.2006.12.013. 